\title{
The Question of Reputational Risk: Perspectives From An Industry
}

\author{
Ernst Csiszar and Gregory W. Heidrich ${ }^{1}$ \\ Policy Development and Research, Property Casualty Insurers Association of America (PCI), 2600 \\ S. River Road, Des Plaines, IL 60018, U.S.A. E-mail: gregory.heidrich@pciaa.net
}

This paper explores the question of reputational risk from an insurance industry perspective. The paper discusses the sources of reputational risk in the insurance context and points to reputational concerns that arise at both the individual firm and industry level. The paper suggests that many reputational risks arise from economic and social factors outside the industry but still carry significant implications for the industry and for insurers operating within it. The paper finally discusses some of the implications of reputational risk for public policy issues facing the insurance industry today and offers thoughts on how those risks must be addressed. The paper concludes that reputational risk is a particularly important issue for the insurance industry, given the nature of the underlying transactions themselves and the public policy challenges the industry faces. The paper concludes that the industry must continue to build its capabilities for addressing this risk.

The Geneva Papers (2006) 31, 382-394. doi:10.1057/palgrave.gpp.2510096

Keywords: reputation; reputational risk; insurance industry; reputation and insurance; reputation and public policy

\section{Introduction}

The question of reputational risk is much discussed in business literature today and is an issue of significant attention and discussion among business leaders, observers, policymakers and indeed those who work in business. Given the corporate governance scandals of recent years, the importance of a good reputation is taken as a given in business today.

A good reputation is seen as a significant intangible asset. In much of the popular discussion of this issue, there is an assumed relationship between having a good reputation and stronger performance for the business or, often, lower costs or other risks. Typical of this view are comments offered recently by the CEO of Pfizer and Chairman of the Business Roundtable, Hank McKinnell. In an interview with the New York Times, McKinnell stated, "My view is that unless we rebuild public respect, regulation and litigation will affect all aspects of our business." Further, "We have recognized that this is a major issue for us, regaining public trust and public appreciation.",2

Some of the literature, popular and academic, asserts that reputation matters more to some types of business than to others and, in particular, matters more to service industries than to manufacturing businesses or producers of tangible products.

${ }^{1}$ The authors are, respectively, President/CEO and Senior Vice President - Policy Development and Research, for the Property Casualty Insurers Association of America (PCIAA).

${ }^{2}$ Holstein (2006). 
Scholars of business reputations Charles Fombrun and Christopher Foss quote recently retired Federal Reserve Chairman Alan Greenspan in a Harvard commencement address saying, "In today's world, where ideas are increasingly displacing the physical in the production of economic value, competition for reputation becomes a significant driving force propelling our economy forward. Manufactured goods often can be evaluated before the completion of a transaction. Service providers, on the other hand, usually can offer only their reputations."3

The developing academic literature on reputation suggests strong reasons why this would be the case, and it rings true for most business observers and practitioners.

Most of the literature on reputation appears to focus more on "firm level" questions of reputation than on industry level questions. Part of this focus seems logically to arise from the fact that a "reputation" is a concept typically ascribed to a single "actor," someone or something that has an ability to take certain actions to control and shape its own behavior. It is easy to think of a person or an individual organization having a reputation arising from its own actions, and having the ability to shape a reputation. It is harder to imagine the same for an entire industry. Further, we would suggest that this focus arises in part from the simple fact that it is easier to identify things a single actor can do to affect or improve that reputation. The concept simply seems to work better at the individual or firm level than at the level of an entire industry.

At the same time, the perspective we bring to this issue is necessarily an industry perspective. As executives of a major service industry trade association and of an industry, moreover, that is both highly regulated and deeply engaged in issues of great public policy importance, our perspective focuses on the reputation of an entire industry. As such, we deal with issues that affect how an industry is perceived by policymakers, the media, and the public, and bring perspectives to this issue arising from that experience.

At an industry level, issues of reputation are important and perceived as such by stakeholders. There is little debate about the importance of reputation, but much less agreement about how, at an industry level, to protect a good reputation or rebuild one that has faltered. Indeed, our observation is that much of the practical work done on reputations, even industry reputations, tends to occur most often through efforts of individual companies and their executives, rather than as an industry effort.

Nevertheless, there is much that can and should be done at an industry level and by industry organizations to build and defend the reputation of an industry. In the material that follows, we hope to offer some observations based on our own experience and suggest some guiding principles that will help those concerned with this issue.

\section{What is a corporate reputation?}

\section{Dimensions of reputations}

Fombrun and Van Riel $^{4}$ identify five distinct academic literatures that have examined questions of reputation, offering perspectives on the economic and strategic implications

\footnotetext{
${ }^{3}$ Fombrun and Foss (2001).

${ }^{4}$ Fombrun and Van Riel (1997).
} 
of reputations, marketing and branding implications, organizational structure questions, the sociological perspective, and accounting perspectives. As Fombrun and Van Riel conclude, corporate reputations fill a number of important roles:

- they are "external reflections of a company's internal identity";

- they establish "mobility barriers" both for the company in question as well as potential rivals;

- they "summarize assessments of past performance by diverse evaluators";

- they provide "an appraisal of firms' economic performance and an appraisal of firms' success in fulfilling social responsibilities."

They offer a new formal definition of corporate reputation:

A corporate reputation is a collective representation of a firm's past actions and results that describes the firm's ability to deliver valued outcomes to multiple stakeholders. It gauges a firm's relative standing both internally with employees and externally with its stakeholders, in both its competitive and institutional environments. ${ }^{5}$

\section{Information asymmetries}

At the heart of many of these topics is the point that corporate reputations are important because of information asymmetries. Since it is impossible for outsiders to know as much as they want or need to know about how a firm will perform, its reputation is a key factor in helping a consumer make a choice. As Fombrun and Van Riel argue, "Since many features of a company and its products are hidden from view, reputations are information signals that increase an observer's confidence in the firm's products and services." ${ }^{6}$ Many have suggested that the importance of a reputation is even greater when the product or service is less well understood by consumers and/or will be delivered far in the future.

As practitioners in insurance public policy issues, we would suggest that insurance products easily fit the characteristics above. Insurance products are complex legal contracts that can be poorly understood by consumers, particularly personal insurance consumers. Beyond the contract itself, key features of how an insurer will deliver its ultimate service, the settlement of a claim, can also be difficult or impossible to know in advance. Probably the vast majority of insurance consumers have little or no frequent direct experience with the insurance claiming process. If they have ever made an insurance claim, they may go years between claims and, thus, be dealing with an entirely different insurer and entirely different set of facts each time.

In addition, we would suggest that an additional factor may be at play in considering insurer reputation. Namely, whenever consumers typically make a claim for insurance coverage, they do so at a time of stress and relative weakness. The claim arises only after they have sustained a loss and, in the worst cases, when they may still

\footnotetext{
${ }^{5}$ Ibid.

${ }^{6}$ Ibid.
} 
be suffering shock at the loss of a home and possessions or personal injury; it may represent significant value or a very high proportion of their personal net worth; and they may feel they do not understand the contract very well. In contrast to other major financial transactions (e.g., the purchase of a home or automobile), the occurrence of an insured loss is unexpected and unanticipated. Life has been turned "upside down."

Given these circumstances, it should hardly be surprising that an insurer's reputation - that is, how it treats claimants and its ability to fulfill its promises - is vital to the transaction. A good reputation is important to most firms, but for insurers, it is vital. It should be no surprise that so much of insurer brand development and investments are devoted to the development of a good reputation for consumer treatment and financial soundness.

\section{Reputations at an industry or political level}

It is a little more difficult to think of a reputation as extending not just to an individual firm but also to an industry as a whole, but we would argue that it is often done. At the most simplistic level, we all know that consumers form an opinion of an industry that industries have reputations. Based on our own experience in one industry, we would suggest that key aspects of that reputation are formed (or re-formed) in times of crisis or change for an industry. In particular, the insurance industry's reputation as a whole is powerfully influenced by how the work of its individual members or players is perceived during moments of crisis (e.g., Hurricane Katrina or 9/11).

While there may be many implications for individual firms or the industry that arise from events such as these, we would cite political implications particularly. When an industry is heavily regulated, as insurance is, it is no surprise that a poor reputation can have major political implications. We suggest that whenever the insurance industry's reputation for handling claims in a crisis is not seen as stellar, proposals for burdensome new laws and regulations are sure to follow.

\section{Is reputation management a fad?}

Is reputation management just the latest in a long line of management "fads?" Is the attention this topic gets today a passing focus that will disappear with the next turn of the business cycle and the next hot topic? Based on our perspective, we do not think so. Clearly, there is a developing academic and practical literature that explores multiple aspects of reputational risk and relates it to many aspects of business operations today. Moreover, from the perspective of an industry organization, we see that reputations are significant, perhaps the key determinant in political reactions to the crises that face any industry periodically.

\section{Factors affecting our views of reputations}

There are a number of factors we believe affect business reputations, some unique to a given situation, but others that are more general and that arise from the nature of capitalism itself. These include some aspects of the development of market systems and 
capitalism itself; a long history of intellectual disagreement over the proper role of business in a capitalistic society; periodic outbreaks of scandals, typically arising from greed, malfeasance, incompetence or all of the above and resulting in new demands for stronger corporate governance; and a general (and recently, it seems to us, growing) public lack of confidence in institutions of all types. All of these factors, we believe, feed into the concern about corporate reputations.

\section{Capitalism}

The history of the development of capitalist economies is one of boom and bust, cycles of ascent and descent, innovation, and the impact of "creative destruction." Numerous scholars and historians of business have noted the tendency and the need for growing societies to experience these patterns and cycles of creation and destruction and creation again. Much of the basis of government regulation and control of business is built on the public consensus that the worst effects of these cycles must be managed and controlled to prevent the most harmful effects.

The patterns of boom and bust and creative destruction mean (in our view) that businesses will frequently face fallout from such cycles and that businesses caught up in a period of great change will face even more pressures. Simply put, when the economy is in the midst of great change, we believe there is greater chance and a higher likelihood that corporate reputations will be an issue of concern. In addition, in a time when much secular change is already occurring, we would suggest that additional changes or shocks will have a greater impact and create more pressure on corporate reputations. Harkening back to our discussion above, we would suggest that any period of significant corporate change is also likely a period in which information asymmetries are particularly significant. Almost by definition, when significant secular change is underway, the informational asymmetry becomes greater and the value of a reputation as a signalling device to a variety of publics becomes greater as well.

\section{The proper role of business}

Second, there is a long history of intellectual disagreement about the proper role of business in a capitalistic society. In our own time, two opposite schools of thought can clearly be seen, but they represent only extreme cases or archetypes of many different perspectives. On the one hand, there has frequently been a school of thought (typically thought of as "conservative" or laissez-faire) that says, "the business of business is business..." This view, at its extreme, seems to suggest that the social responsibility of a business is to make money within the law for its owners or shareholders and, if there is any other social responsibility to be ascribed to anyone, it is to the shareholders themselves as members of the society who have responsibility. Under this point of view, one could argue that the reputation of a firm is irrelevant, so long as the share price and returns provided to the firm's owners are at levels consistent with rewarding capital appropriately. In this view, one could almost suggest that the only reputation that matters is a reputation for delivering competitive returns to owners. 
A second viewpoint could be characterized as the extreme social responsibility perspective, often ascribed to consumer activists such as Ralph Nader or others. Proponents of this extreme view appear to suggest that profit is somehow inappropriate and to argue that business has significant social responsibilities well beyond the demands of earning a competitive return. In this view, business is a social institution with responsibilities for care of the community, the environment, its workers' health care (while working and retired), retirement incomes, and many other obligations. At the extreme end of this viewpoint, businesses may be seen as little more than social or human service agencies with a variety of funding mechanisms. Much of the recent criticism levelled against retail giant Wal-Mart would seem to be of this nature, ascribing to them a responsibility to protect communities and businesses in those communities from the "ravages" of low prices voluntarily paid by consumers. In this view, the reputation of a business matters critically not so much to resolve information asymmetries, but as a measure of the firm's success in meeting its wideranging social obligations.

Most observers of capitalist society and business organizations today easily fit between these two stereotypes, arguing that any business must provide an appropriate return to its shareholders, but that businesses also have a series of non-financial obligations to their communities, employees, and the public that must also be met. Indeed, most corporate annual reports today are at great pains to demonstrate care and concern for meeting these social obligations while still reaching financial performance goals that will reward shareholders appropriately.

\section{Scandals}

There is little doubt that capitalistic societies and systems experience periodic scandals. Even as this is written, the trial of two former CEOs of the Enron Corporation, representing one of the largest bankruptcies in U.S. history, is underway. No recounting of the many problems caused by this failure including, not least, the related downfall of the Arthur Andersen accounting firm that fell almost entirely due to damage to its reputation, is needed. It is clear that scandals of the "Enron, Worldcom, Adelphia, Tyco"-type spawn a great deal of concern about corporate reputations and much research into how such damage can be prevented or better controlled.

More damaging, perhaps, such scandals have historically also spawned legislation intended to prevent future scandals, but more accurately aimed at preventing the scandal that already happened. In this vein, the latest outbreak of legislation is no different, spawning the Sarbanes-Oxley reforms of corporate governance and imposing large compliance burdens on American business. It is not without irony that the costs of these "reforms" typically fall most heavily on businesses that did not need this legislation to be ethical and is paid for, ultimately, by the consumers it was intended to protect. How much benefit such reforms can provide to business reputations is a different (and more difficult) matter entirely. It will be an interesting area of research to examine the extent to which (if any) the expense and burden of Sarbanes-Oxley compliance has improved the reputations of American businesses or their odds of avoiding future scandals. 


\section{Public doubts about institutions}

Finally, we would suggest that some of the recent concern with business reputations also arises from a more general concern with the performance and behavior of a variety of institutions. Put another way, it is not only business leaders who are concerned about their reputations today - we would suggest that we are currently in a period of widespread public doubt and lack of trust in a variety of institutions, including government, schools, religion, and many other areas.

To offer only a few of the many examples possible, we note the extremely partisan nature of politics in Washington and many state capitals. While there have always been such periods in American history and a longer perspective in such matters is invaluable, we note that many practitioners suggest that the current lack of public trust, driven in no small measure by obvious and egregious government failures, is extreme and has many negative effects on the ability to create and implement reasonable policy solutions to problems the nation faces. Clearly, concern about the reputation of government and policymaking itself is significant and a source of much thought among policymakers.

Examples of reputational concerns for each of the institutions cited above are easy to come by and simply reiterate the point that problems of reputations are widespread. It should be no surprise, then, that business institutions are subject to the same concerns and should be focused on finding solutions. In a time when reputations of so many institutions are at risk, it should be of little surprise that business finds itself in the same boat.

\section{Property/casualty insurance industry applications}

As noted above, the authors' experience lies in public policy affecting the property/ casualty insurance industry and it may be helpful to identify or suggest particular reputational difficulties insurers face today. Clearly, insurance is a business facing problems of asymmetrical information vis-à-vis its customers, regulators, and the general public. Its product is a complex legal contract, built on a promise to pay benefits in the future if an uncertain event happens. If there were ever an industry where a good reputation, as a signalling device, would be important, property/casualty insurance is one. Industry participants sometimes joke (but it may be no joke) that the insurance product is "no fun to buy and less fun to use," creating significant difficulties for any insurer in developing, maintaining, and protecting a good reputation.

Property/casualty insurers are deeply concerned today with reputational issues. We will discuss several that arise in connection with some of the industry's most significant public policy issues and suggest the reputational issues at stake.

\section{Catastrophe exposure}

The most significant issue facing the industry today is likely its exposure (and the exposure of its customers) to major natural catastrophes. As Hurricane Katrina (and a 
number of other major recent natural catastrophes) demonstrated, the industry and its customers face major financial exposures from these events. That much has always, however, been known and much thought and research are done in the industry to prepare for and address this exposure.

Less well-appreciated, pre-Katrina, is the exposure to the industry's reputation that a major natural catastrophe can pose and the risks it can pose for the industry's regulation, its future pricing, and even share prices of publicly traded insurers. Because of the widespread devastation Katrina caused, including particularly the heavy flooding in New Orleans, the industry's settlement of claims has been perceived by some in the affected areas to be slower than expected. In addition, the distinction between damage caused by water and damage caused by wind, long a tenet of insurance coverage, has come under unprecedented legal attack even by authorities of the government. Many criticisms have been levelled at the industry for its handling of this disaster (albeit many fewer than have been aimed at the government response) and the industry's reputation has no doubt sustained damage.

From the industry's perspective, these criticisms are sometimes seen as unfair. Many in the industry believe that a worthy job, indeed an heroic effort, was undertaken, particularly given that it came on the heels of a very difficult hurricane season in 2004. Clearly, the industry and individual firms within it face significant reputational risk from events such as these. Future research and examination, both by the industry and by those who study it, is needed to understand the precise sources of this risk and the factors that influence the public's perception of why the industry's response may not have met the expectations of some constituencies and how that risk can be managed in the future. In addition, research is needed on exactly what consumers expect from insurers in extreme catastrophe situations; how those expectations differ from those that exist when there is no crisis; and what steps can be taken to control or manage the risk.

\section{Partnerships with others - e.g., government}

Related in one specific case to the catastrophe exposure issues, but a potentially broader problem, is the risk to reputation that arises from partnership arrangements with providers of related services or coverages. Illustrating the case is the reputational damage that arises from non-performance or perceived poor performance by the partner.

The U.S. National Flood Insurance Program (NFIP) has been widely perceived by the public not to have performed well in recent years. Congressional hearings have focused on claim-related problems arising from several recent floods and natural catastrophes, and there is widespread agreement that the program must be reformed. The program itself is a partnership arrangement between the federal government and the industry. The essential features of the program, including coverage provided and the price charged, are established by the government because all claims are ultimately paid by the government. Private insurers act as servicing carriers for a fee.

Arising from the Hurricane Katrina experience, two reputational risk exposures can be seen. First, the administration of the program as designed can create significant 
reputational risks, both with the consumer and with the partner. For example, insurance claim representatives typically make adjustment decisions regarding the allocation of damage between what is covered under the insurer's own policy (broader coverage) and what is covered by the government program (narrow coverage). Critics of the flood program, including members of Congress, plaintiff attorneys, and others, have recently begun to attack insurers' decisions in these cases as unfairly shifting costs to the government and of enhancing insurers' financial performance at the expense of both the government and the individual consumer. To the extent such allegations gain credence, insurers face threats to their reputation with their program partner (the government) and with the public at large. The reputational risk in this case arises even when the program performs as designed.

A second example in this case arose quite significantly in the immediate aftermath of Hurricane Katrina. The volume of claims from that storm overwhelmed very early on the retained assets of the program, requiring Congressional appropriation of additional funds to pay contractually mandated claim payments. Insurers faced a significant risk that, should Congress not provide the needed funds, insurers would be forced to tell their policyholders that funds were not available to pay claims owed. In this case, insurers feared significant damage to their own reputations, arising from non-performance by their partner. Insurers feared that customers would be unable (or unwilling) to distinguish between the actions of the government and the actions of the insurer, holding both accountable. The risk was diverted by a series of legislative steps after intensive lobbying by the industry.

Obviously, this is an extreme case, but it illustrates the point that insurers (and other businesses) face significant reputational risks from the actions or non-actions of business partners. Insurers operate in networks of significant partnership arrangements, including agency relationships, insurer-to-insurer partnerships or risk-sharing arrangements, reinsurance treaties, and public/private partnerships. These risks are magnified when one party (the insurer in the NFIP case) has little or no control over the actions of the partner. While perhaps less common in most business transactions, such a lack of control is common in arrangements with the government. It is an obvious point that if one can only deliver a product or service to an end-customer if a partner delivers its share of the bargain, then one is at significant reputational risk due to the actions of the partner.

\section{Terrorism}

Terrorism risk has been a preoccupation of the industry, particularly the workers compensation and commercial property lines, since $9 / 11$. At times, it has seemed to practitioners as if the entire public policy focus of the industry since $9 / 11$ has been about one thing, terrorism risk and the government's role in it. The lobbying efforts to gain first the enactment and, later, the extension of the Terrorism Risk Insurance Act (TRIA) have been almost unprecedented in the degree of sustained industry effort and consensus of approach.

At the same time, there are clearly tensions and concerns within the industry and within the issue itself that pose issues of reputational risk for insurers now and in the 
future. First, the industry and many policymakers believed in 2001 that the industry faced a critical moment of "reputational exposure" as individual firms considered how to respond to the attacks of 9/11. On 9/11 itself, the President declared the attacks to be an "act of war" and questions were raised in the media and in Congressional hearings whether the industry would seek to invoke act of war exclusions in policy language. As we know, that didn't happen and a potential reputational crisis never materialized.

At the same time, with the federal government's backing of terrorism risk slated to end in 2007, the industry faces important questions about its own role in providing future protection against terrorism risk. Many policymakers have pushed the industry to accept a greater (or even the entire) role of providing protection against this risk, even as many industry observers and experts believe the risk is entirely uninsurable. What risks does the industry face if individual companies were to decide, in a postTRIA world, that terrorism is uninsurable and refuse to provide coverage? What does the public expect insurers to do in a case like this? How much understanding does the public have about the financial pressures insurers may face and how they should address such pressures?

Moreover, while almost all of the public debate on this issue has focused on the commercial insurance exposures from terrorism, knowledgeable industry experts have begun to point with concern to the potential exposure facing American homeowners from a so-called Nuclear, Biological, Chemical, or Radiological (NBCR) event. ${ }^{7}$ These experts have suggested that a number of residential property insurance policies may (or do) contain limitations on the coverage provided on residential property from such sources, but that these limitations can vary significantly by insurer and by jurisdiction. In the event of a catastrophic NBCR-type terrorist attack on residential properties, there would appear to be the potential for significant reputational risk for insurers who must then inform their customers that the damage suffered was not insured. The industry's recent experience with questions (and politically motivated litigation) arising from the so-called wind versus water debate can only be sobering in this regard.

\section{Rating and underwriting factors - the case of credit scores and other similar tools}

The industry has made significant strides in recent years in applying new modelling and data mining tools to its business. The insurance underwriting and rating process, particularly in the personal lines, has become extraordinarily complex and sophisticated. Knowledgeable observers of the industry suggest that those

\footnotetext{
${ }^{7}$ NBCR commonly refers to the risk of loss arising from the use of NBCR agents. Clearly, such attacks are commonly discussed by policymakers and credible allegations of attempted attacks or threats of attacks have been made (e.g., the case of Jose Padilla). In the industry, such attacks are commonly seen as those posing the greatest potential damage to property and life in the United States. Modelling for such events has identified potential losses of a truly catastrophic nature. See, for example, Statement by American Academy of Actuaries TRIA Subgroup on Extending or Replacing the Terrorism Risk Insurance Act of 2002 (TRIA), 1 December, 2005. The report suggests that as much as $\$ 700$ billion of insured losses could occur from an NBCR attack.
} 
insurers most able to take advantage of this technology and most able to attract and retain the analytical talent able to do so will be winners in an increasingly competitive market.

At the same time, the rise in the use of such tools has introduced to the underwriting and rating process factors and data elements that do not appear to non-industry members (e.g., customers and the public at large) to have any intuitive connection to insurance claims. Commentaries offered by members of the public, putative consumer representatives, and even some regulators routinely assert that unless a particular data element (e.g., an individual's credit score) can be shown to have an intuitive causal relationship to a loss, its use should not be allowed. Although most discussion of this issue in recent years has focused on the use of credit-related information, the recent public debate regarding the use of such factors as occupation and educational attainment confirm the point.

We would suggest that the industry faces significant ongoing reputational risks from its development of its underwriting and rating technologies. That is not to suggest in any way that such development should be slowed or discontinued; quite the contrary. It does suggest, however, that insurers individually and as an industry will face ongoing issues of reputational risk management arising from these developments. In particular, they will face challenges of continually educating consumers, the media, policymakers, and the public at large about the rating and underwriting process, the benefits of continued technological improvements in these processes, and the connections between these factors and underlying risks.

\section{Accounting standards}

A final area of brief mention is the potential reputational damage that can be done from an otherwise well-intended regulatory rules change. Changing rules governing accounting or legal standards for the industry can significantly alter market and public perceptions of the industry, as well as change insurers' underlying behavior. In doing so, they can affect insurer reputations in significant ways and alter the signals a reputation is sending to potential business partners or customers.

A case in point is the ongoing effort to develop new international insurance accounting standards. A key issue in this effort is the attempt to place a market value with a risk premium on insurer liabilities. Many U.S. insurers have suggested that this effort, however well-intentioned, would place them in the position of having to mark liabilities not to a recognized market standard, but to an untested and unproven model. The concern among these insurers is that the model itself is unproven and may be unreliable. If true, any resulting volatility in insurer liabilities might reflect only the model's own or induced volatility, rather than the underlying economics of the business itself.

An insurer's reputation is inextricably bound up with public perceptions of financial solidity and stability. New tools to measure financial condition can have a significant impact on insurer reputations and, for that reason, are a major focus on industry efforts to manage reputational risk. 


\section{Conclusions}

This paper has explored various aspects of reputational risk and its implications for insurers. We have noted that reputational risk arises from many sources and has many dimensions. In particular, we have observed that the nature of the insurance transaction poses distinct and very serious issues of reputational risk for insurers. We have suggested further that these issues arise at both individual firm and industry levels and must be addressed at both levels. We have also suggested that many reputational risks arise as well from economic and social factors outside the industry itself, including factors tied to the history of the development of capitalist society itself, political disagreements over the role of business within a capitalist society, periodic corporate scandals (e.g., Enron), and a generalized decline in public confidence in many institutions (e.g., business, government, religion, and education). Finally, we have discussed several key public policy issues facing the insurance industry, the reputational risks they pose to insurers today, and offered thoughts on how they must be addressed by insurers.

This is (obviously) not an exhaustive exploration of the question of reputational risk nor of the risks insurers face, individually or collectively. We believe, however, that it suggests the nature of the reputational risks insurers face today and the need for ongoing, thoughtful consideration of these risks. In particular, we believe it will be ever more vital that the industry consider reputational risk explicitly, as individual firms, and collectively in its public policy development activities. We believe further that the industry will need to focus attention and resources on building its capabilities and skills in addressing the unique questions posed by reputational risk.

\section{References}

Fombrun, C.J. and Foss, C.B. (2001) 'The Reputation Quotient. Part 1: Developing a Reputation Quotient', The Gauge - Delahaye Medialink's Newsletter of Worldwide Communications Research 14(3), 14 May 2001.

Fombrun, C.J. and Van Riel, C. (1997) 'The Reputational Landscape', Corporate Reputation Review 1(1-2): 5-13.

Holstein, W.J. (2006) 'The impact of image on the bottom line', The New York Times, 9 April 2006.

\section{About the Authors}

Ernst Csiszar is President and CEO of the Property Casualty Insurers Association of America (PCIAA). Mr. Csiszar was appointed to his current position in August of 2004. Prior to joining PCIAA, Mr. Csiszar established a distinguished reputation in the insurance industry as a company executive, regulator, and national leader. In 1999, he was appointed director of the South Carolina Department of Insurance, where he served until 2004. He assumed leadership positions within the National Association of Insurance Commissioners, serving as secretary-treasurer, vice president, and president. Prior to his appointment as director of insurance, Csiszar served as President and CEO of Seibels Bruce Group, a Columbia, South Carolina, insurance company from 1995 to 1998. He was a visiting professor at the School of Business at the University of South Carolina from 1993 to 1995 and served as managing co-director of the 
European investment banking firm Holborn Holdings Corporation in Geneva from 1979 to 1988. Mr. Csiszar is a graduate of the University of Windsor (Canada), with a Bachelor of Arts in Mathematics and Philosophy. He received his LLB from the University of Windsor School of Law.

Gregory W. Heidrich is Senior Vice President, Policy Development and Research, for the PCIAA. Mr. Heidrich is responsible for development of policy positions and supporting research on public policy issues facing the property/casualty insurance industry and members of PCIAA. Prior to his current appointment, he has held positions directing public policy development for commercial lines and workers compensation issues and directing economic and public policy research for the Alliance of American Insurers, a predecessor trade association to PCIAA. He has also served as Secretary and Treasurer for the Alliance. Mr. Heidrich earned his Master of Arts in Economics from the University of Chicago and is an honors graduate (Economics) of the University of Oklahoma. 